\title{
Partitioning the plant diversity of semi-natural grasslands across Japan
}

\author{
Asuka Koyama, Tomoyo F. Koyanagi, Munemitsu Akasaka \\ Yoshinobu Kusumoto, Syuntaro Hiradate \\ Masayuki Takada and Kimiko OKabe
}

\begin{abstract}
Effective conservation of global species diversity requires a clear understanding of spatial scales that support overall diversity across broad scales. Abandonment of seminatural grasslands has increased their fragmentation and decreased their areal extent. We quantified diversity patterns of plant communities in Japan across hierarchical scales to facilitate the development of an effective nationwide strategy for conserving species diversity in remnant semi-natural grasslands. We applied additive partitioning of plant species diversity, using a nested hierarchical design at three spatial scales (quadrat, grassland, and western and eastern regions of Japan) for three groups of plant species (all species, grassland species and national Red Listed species). We consistently found lower proportions of amongquadrats diversity, and higher proportions of among-grasslands diversity and between-regions diversity in the overall diversity of the entire species complement than would be expected by chance. The high contribution of among-grasslands diversity to overall diversity suggests that each grassland had a unique species content. The second-ranking contributor to overall diversity differed between grassland species and Red Listed species: the second-ranking contributor for grassland species was diversity at the amongquadrats scale but the second-ranking contributor for all species and for Red Listed species was diversity at the between-regions scale. Thus, effective conservation of diversity of the entire species complement in remnant seminatural grasslands requires preservation of beta diversity in individual grasslands. Our findings highlight the importance of strengthening local preservation and restoration activities within each grassland, and of nationwide strategies
\end{abstract}

\footnotetext{
AsuKa Koyama (Corresponding author) and Kiмiко Oкаве Forestry and Forest Products Research Institute, Tsukuba, Ibaraki, 305-8687, Japan

E-mail asukoyama@gmail.com

Tомоyo F. Koyanagi Field Studies Institute for Environmental Education, Tokyo Gakugei University, Koganei, Tokyo, Japan

Munemitsu AKasaka Faculty of Agriculture, Tokyo University of Agriculture and Technology, Fuchu, Tokyo, Japan

Yoshinobu Kusumoto and Syuntaro Hiradate National Agriculture and Food Research Organization, Institute for Agro-Environmental Sciences, Kannondai, Tsukuba, Ibaraki, Japan

MASAYUKi TAKADA Faculty of Humanity and Environment, Hosei University, Chiyoda, Tokyo, Japan

Received 28 April 2016. Revision requested 4 August 2016.

Accepted 9 November 2016. First published online 20 February 2017.
}

for conserving Red Listed species in remnant semi-natural grassland communities.

Keywords Beta diversity, biodiversity conservation, grassland, Japan, Red Listed species, semi-natural grassland, spatial scale, species richness

Supplementary material for this article can be found at https://doi.org/10.1017/So030605316001526

\section{Introduction}

$\mathrm{O}$ ngoing losses in global biodiversity as a result of the overuse or underuse (e.g. land abandonment) of land by human populations necessitate increased efforts to conserve species across broad spatial scales. Variability in the patterns of biodiversity across spatial scales has been a focus of conservation ecology in recent decades (Summerville et al., 2003; Coetzee et al., 2014). These patterns are regulated by multiple environmental variables over fine and broad scales (Groves et al., 2002; Luoto et al., 2007). The identification of important spatial scales that support all elements of species diversity is essential for the effective allocation of limited conservation resources (Jost et al., 2010). Although broad-scale conservation studies that incorporate geographical variability have become more common (Crist et al., 2003; Gering et al., 2003; Müller \& Goßner, 2010), there have been few investigations of species diversity patterns at national or continental scales (Luoto et al., 2007). Broad-scale conservation is especially important for the preservation of species diversity in remnant and fragmented ecosystems, including fragmented forests, remnant grasslands and montane moorlands (Wagner et al., 2000; Martin et al., 2005; Sasaki et al., 2012).

Species-rich, semi-natural grasslands were maintained for centuries by human management activities (e.g. burning, mowing, grazing); their abandonment during shifts to modern agricultural practices has increased fragmentation and reduced the landscape areas under grass (Kahmen et al., 2002). Although preservation and restoration efforts aimed at conserving biodiversity have made some progress in remnant semi-natural grasslands (MacDougall \& Turkington, 2007), most of these efforts have been applied locally (i.e. single grasslands), without considering regional or national scales. Local-scale preservation and restoration 
efforts often focus only on the responses of particular threatened species (e.g. local Red Listed species) (Vellak et al., 2009), without taking account of net species diversity losses (Lennon et al., 2011; Chiarucci et al., 2012). Although plant species diversity in semi-natural grasslands has been well studied at diverse spatial scales (Hansson \& Fogelfors, 2000; Myklestad \& Sætersdal, 2004; Auestad et al., 2008), identification of important scales for effective conservation of all species is notably lacking.

The areal extent of semi-natural grasslands in Japan has declined rapidly since the 1960 os because of abandonment, land development and the proliferation of coniferous plantations (Takahashi, 2004; Ogura, 2006; Nagata \& Ushimaru, 2016); these grasslands now comprise $<1 \%$ of the nation's total land area. Montane semi-natural grasslands exist in isolation across Japan, and most have been preserved and designated as national parks or quasi-national parks.

Our aim was to identify important spatial scales for conserving entire species complements, thereby facilitating the development of an effective nationwide strategy for the preservation of remnant semi-natural grasslands. Additive partitioning of species diversity is a useful approach for quantifying the spatial patterns of biodiversity sampled in hierarchically scaled studies (Lande, 1996; Veech et al., 2002; Crist et al., 2003). This approach facilitates additive partitioning of the total diversity in an area into scalespecific diversity components (Wagner et al., 2000; Veech et al., 2002; Gering et al., 2003) and identifies the spatial scale most relevant to the conservation of the entire species complement. We applied procedures for additive partitioning of diversity to vegetation datasets assembled for representative montane semi-natural grasslands across Japan. Species diversity patterns across spatial scales may vary with the geographical range of individual plant taxa (i.e. whether they are widespread or narrowly distributed; Crist et al., 2003; Gering et al., 2003; Müller \& Goßner, 2010). Thus, we aimed to identify the most important elements of overall species diversity, with a particular focus on grassland species and Red Listed species. We discuss appropriate spatial scales for the allocation of preservation and restoration efforts that best conserve species complements nationwide.

\section{Study sites}

The study was conducted in 11 montane semi-natural grasslands across Japan (Table 1; Fig. 1), excluding the islands of Okinawa and Hokkaido, spanning most of the representative, historically managed montane grasslands in the country. The grasslands (Aso, Shiozuka, Akiyoshi-dai, Mt Ungetsu, Mt Sanbe, Hiruzen, Soni, Asagiri, Sengokuhara, Minakami and Kawatabi) are located in a range of climatic zones, from warm-temperate to cool-temperate. All of the locations were managed through regular spring burning and/or seasonal mowing procedures. In some of the grasslands (e.g. Mt Ungetsu, Sengokuhara, Minakami), management activities were suspended temporarily after World War II and/or the earthquake disaster in 2011 but had been resumed 2-10 years prior to the study. The grass Miscanthus sinensis Andersson predominates in continually managed grasslands in Japan (Koyanagi et al., 2013); Pleioblastus argenteostriatus (Regel) Nakai and Sasa veitchii (Carrière) Rehder were also dominant in some of the grasslands studied.

\section{Methods}

\section{Survey design}

During June-September in 2010, 2011 and 2015 we conducted vegetation surveys in each grassland. We set 24-74 quadrats $\left(1 \times 1 \mathrm{~m}^{2}\right)$ at random, according to the area of each grassland, deployed across a range of topographies. Characteristic species in M. sinensis-dominated communities were categorized as grassland taxa (Koyanagi \& Furukawa, 2013). Red Listed species of vascular plants were identified using the national Red List (Ministry of the Environment, Government of Japan, 2012) and the Red Lists for the 45 prefectures, to include the entire range of listed species (excluding those on Okinawa and Hokkaido). We extracted species categorized as Extinct, Extinct in the Wild, Critically Endangered, Endangered, and Vulnerable from these Red Lists. Red Listed tree and shrub species (21 species) were not included in the study.

The vegetation data were compiled in a hierarchical nested matrix (Table 1). The three hierarchical levels corresponded to the following spatial scales: regional (western vs eastern Japan), grassland (0.1-220 $\mathrm{km}^{2}$ ), and quadrat (491 quadrats, each $1 \mathrm{~m}^{2}$ ). The plants were grouped into three categories: all species, grassland species and Red Listed species. At the regional scale the variation in the geological structure of the Japanese islands, which are split by the Fossa Magna rupture zone (Maekawa, 1949), was evident. The western and eastern regions included seven and four grasslands, respectively.

\section{Statistical analysis}

To determine the adequacy of our sampling we computed species rarefaction curves for separate grasslands and for all grasslands pooled (491 quadrats in total), with a Monte Carlo permutation of samples (Kobayashi, 1973; Chiarucci et al., 2008), using the specaccum routine in the vegan package of $R$ v. 3.0.3 (Oksanen et al., 2016). In each case a mean species accumulation curve was constructed from data collected by sub-sampling the entire community 1,000 times 
TABLE 1 Details of the 11 semi-natural grassland study sites in Japan, with codes (Fig. 1), number of quadrats, mean number of species per $\mathrm{m}^{2}$, area, elevation, and whether or not burning and mowing are carried out.

\begin{tabular}{|c|c|c|c|c|c|c|c|c|}
\hline No. & $\begin{array}{l}\text { Grassland } \\
\text { (Prefecture; Region) }\end{array}$ & Code & $\begin{array}{l}\text { No. of } \\
\text { quadrats }\end{array}$ & $\begin{array}{l}\text { Mean number of } \\
\text { species } \pm \text { SD }\left(\mathrm{m}^{-2}\right)\end{array}$ & Area $\left(\mathrm{km}^{2}\right)$ & Elevation $(\mathrm{m})$ & Burning & Mowing \\
\hline 1 & Aso (Kumamoto; West) & AS & 74 & $19.4 \pm 6.9$ & $>100$ & $600-800$ & Yes & Partial \\
\hline 2 & Shiozuka (Tokushima, Ehime; West) & SK & 60 & $17.5 \pm 4.7$ & $<1$ & 700 & Yes & No \\
\hline 3 & Akiyoshi-dai (Yamaguchi; West) & $\mathrm{AK}$ & 74 & $16.0 \pm 3.9$ & $<100$ & $200-400$ & Yes & Partial \\
\hline 4 & Mt Ungetsu (Hiroshima; West) & UG & 64 & $18.4 \pm 4.4$ & $<1$ & 900 & Yes & No \\
\hline 5 & Mt Sanbe (Shimane; West) & SB & 28 & $17.2 \pm 3.6$ & $<1$ & $400-600$ & Yes & Partial \\
\hline 6 & Hiruzen (Okayama; West) & $\mathrm{HZ}$ & 25 & $20.6 \pm 6.5$ & $<1$ & 600 & Yes & No \\
\hline 7 & Soni (Nara; West) & SN & 40 & $15.8 \pm 3.3$ & $<1$ & $700-800$ & Yes & No \\
\hline 8 & Asagiri (Shizuoka; East) & AG & 42 & $20.2 \pm 5.4$ & $<1$ & 900 & Yes & No \\
\hline 9 & Sengokuhara (Kanagawa; East) & SG & 30 & $14.6 \pm 4.2$ & $<1$ & 700 & Yes & No \\
\hline 10 & Minakami (Gunma; East) & MK & 24 & $15.0 \pm 3.1$ & $<1$ & 1,000 & Yes & Partial $^{*}$ \\
\hline 11 & Kawatabi (Miyagi; East) & KT & 30 & $5.6 \pm 1.5$ & $<1$ & $300-600$ & No & Yes \\
\hline
\end{tabular}

*The mown area was not identified.

without replacement. Although studies have demonstrated that spatial autocorrelation needs to be incorporated in the calculation of sample-based rarefaction curves (Chiarucci et al., 2009; Bacaro et al., 2016), our data are not suitable for this spatially explicit method because of a lack of coordinate data for some quadrats. Therefore, we used this result only for confirmation of data sampling. We then estimated total species richness non-parametrically with first-order jackknife estimates using the equation:

$$
\text { estimated total richness }=S+r 1(n-1) / n
$$

where $n$ is the total number of samples, $S$ is the number of species observed in $n$ quadrats, and $n$ is the number of species present in only one quadrat (Palmer, 1990).

The contributions of the various spatial components to overall species diversity were quantified by additive partitioning of species richness (Lande, 1996; Crist et al., 2003). In this approach the entire diversity of a sampling unit $(\gamma)$ can be separated into additive components: $\alpha$ (within sampling units) and $\beta$ (between units) diversity (Allan, 1975; Lande, 1996). This additive procedure can be extended across multiple scales in a hierarchical spatial sampling design (Crist et al., 2003). We partitioned total plant diversity across grasslands nationwide into the diversities contributed by each of the spatial scales:

$$
\begin{aligned}
\gamma= & \alpha_{1}(\text { within quadrat })+\beta_{1}(\text { among quadrats }) \\
& \left.\left.+\beta_{2} \text { (among grasslands }\right)+\beta_{3} \text { (between regions }\right)
\end{aligned}
$$

We used species richness as the diversity index (Jost et al., 2010) for the three plant groups (all species, grassland species and Red Listed species).

To test the significance of level-specific $\alpha$ and $\beta$ estimates of diversity partitioning, we tested a null model hypothesis using the adipart function in the vegan package (Oksanen et al., 2016) through a sample-based randomization procedure. The null model hypothesis prediction that species diversity was uniform at all spatial scales was examined by additive partitioning of the total diversity ( $\gamma$ diversity). We used a complete randomization procedure (Crist et al., 2003), repeated 1,000 times to obtain null distribution of each $\alpha$ and $\beta$ estimate for plant species diversity at each spatial scale. Each of the original level-specific estimates was then compared with the appropriate null distribution and used to test the null hypothesis that the observed $\alpha$ and $\beta$ diversities were obtained from a random distribution of individuals among samples at all hierarchical levels. Statistical significance was assessed from the proportions of null values that were greater or smaller than the actual estimates. We are aware that the additive partitioning method across spatial scales has an issue with the lack of independence of $\beta$ and $\alpha$ diversity components (Jost, 2007; Schmera \& Podani, 2013). Nevertheless, the additive method is useful for estimating the contribution of various levels of the sampling hierarchy to overall diversity, and is widely used (Bacaro et al., 2015). For future analyses, more promising approaches consider pairwise dissimilarities and are based on partitioning the dissimilarity matrix of sampling units (Schmera \& Podani, 2013).

\section{Results}

We recorded 390 plant species in total (excluding 48 unidentified species) from the 491 quadrats; the mean number of species was 5.6-20.6 (Table 1). These included 120 grassland species and 171 Red Listed species (66 species in common; Supplementary Table $S_{1}$ ). The number of species accumulated increased with the number of quadrats sampled, and the curves tended to become saturated towards the maximum number of sampling units (Fig. 2). The first-order jackknife estimate of total richness for all grasslands was 469 (Fig. 2b). The observed richness indices 


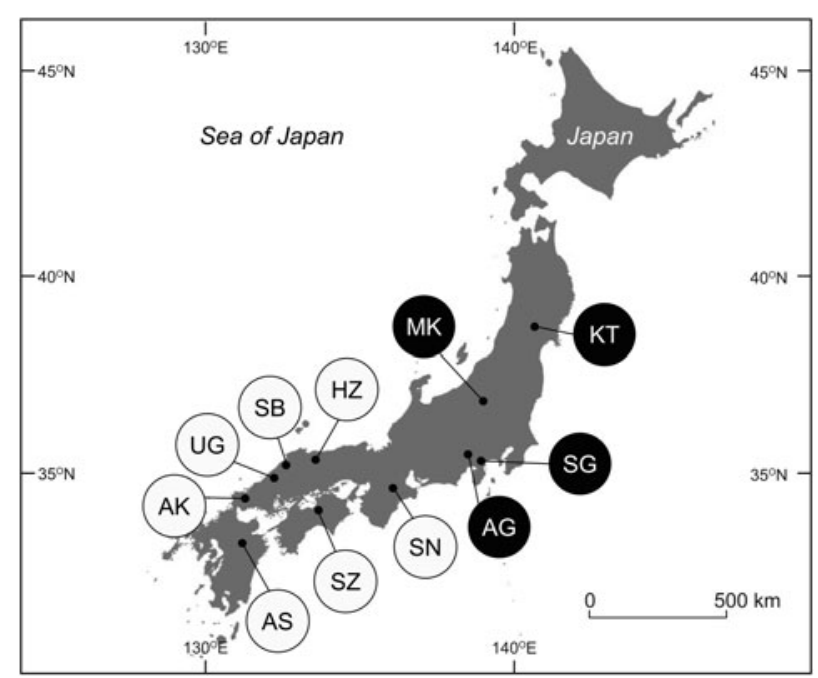

FIG. 1 Locations of the 11 semi-natural grassland study areas in Japan. White circles, western Japan; black circles, eastern Japan. See Table 1 for site codes.

in individual grasslands and across all grasslands were $>75$ and $>82 \%$ of the estimated total, respectively (Fig. 2a,b).

The additive partitioning of species diversity produced consistently higher $\alpha_{1}, \beta_{2}$ and $\beta_{3}$ diversity values than expected by chance for all three plant groups (all species, grassland species and Red Listed species) but the $\beta_{1}$ diversity value was lower than would be expected by chance (Fig. 3). Thus, a non-random ecological process determined species distributions across spatial scales. Differences among grasslands $\left(\beta_{2}\right)$ accounted for the largest proportion of total species richness for the three plant groups across spatial scales. We also found differences between grassland species and Red Listed species in terms of the proportions of total diversity accounted for by different spatial scales. The secondhighest proportions for all species and Red Listed species were accounted for by differences between regions $\left(\beta_{3}\right)$, but the highest proportion for grassland species was accounted for by differences among quadrats $\left(\beta_{1}\right)$.

\section{Discussion}

We found that differences among grasslands $\left(\beta_{2}\right)$ accounted for the largest proportion of total species diversity in remnant semi-natural grasslands across Japan. Thus, nonrandom ecological processes operating at the amonggrassland scale were important determinants of plant species composition and richness. Previous studies have shown that broad spatial scales (e.g. the regional scale) are the most relevant for the conservation of insect assemblages in forest ecosystems (Gering et al., 2003; Müller \& Goßner, 2010) and plants in protected areas or fragmented farmlands (Flohre et al., 2011; Chiarucci et al., 2012). However, intermediate-scale diversity (e.g. between-plot diversity) is the most relevant for the total species diversity of woody plants in temperate forest ecosystems (Chandy et al., 2006). We found that between-region effects were not the largest contributors to overall diversity; among-grassland effects were larger, suggesting that each grassland has a unique grouping of species. In our dataset 186 species (including 24 grassland species and 81 Red Listed species) were recorded from only a single grassland (Supplementary Table $\mathrm{S} 1$ ). Therefore, conserving beta diversity in each grassland is essential for preserving nationwide plant species diversity in semi-natural grasslands.

The contribution of regional-scale effects to overall species diversity is determined by differences in climate, biogeographical factors, historical processes, and dispersal limitation between regions (Gering et al., 2003; Müller \& Goßner, 2010). The relatively high contribution of $\beta$ diversity among grasslands $\left(\beta_{2}\right)$ in our study was probably a result of multiple factors, such as soil type, historical land-use, geographical variation, grassland extent, and seed-dispersal limitation among grasslands. Soil type determines the plant composition and richness of semi-natural grassland communities (Gibson et al., 1993; Kahmen et al., 2005; Auestad et al., 2008). The soils of some of the semi-natural grasslands we studied included limestone (e.g. Akiyoshi-dai) and volcanic ash (e.g. Aso and Sengokuhara). Historical land-use also determines the plant species richness of grassland communities (Hansson \& Fogelfors, 200o). In totally abandoned grasslands (e.g. Sengokuhara and Minakami) the species richness of grassland taxa and Red Listed species has decreased (Grman et al., 2013), probably as a result of increased cover of woody plants (Pykälä et al., 2005). Geographical factors, particularly elevation and aspect, regulate temperature and solar radiation, and can thus determine the distribution of grassland species of northern origin (Marini et al., 2007). The extent of each grassland, in combination with geographical factors (e.g. elevation, slope angle and aspect), is another principal determinant of species turnover (Bennie et al., 2006; Marini et al., 2007; Yamato et al., 2013); however, areal estimation is difficult in mosaic and isolated Japanese grasslands (Table 1). In the largest seminatural grassland in Japan (Aso) we found several endemic species and 119 Red Listed species, including four categorized as Vulnerable at the national level (e.g. Trigonotis radicans Steven and Silene sieboldii (Van Houtte) H. Ohashi \& H. Nakai; Supplementary Table $\mathrm{S}_{1}$ ). Because the distribution of remnant semi-natural grasslands in Japan is limited, identifying the principal determinants of species differences among them is difficult. More detailed studies on the combined effects of soil type, human land-use, grassland extent and geographical factors on plant species diversity should improve understanding of the uniqueness of individual grasslands.

We found that the second-ranked spatial scale contributing to overall species diversity differed between grassland 

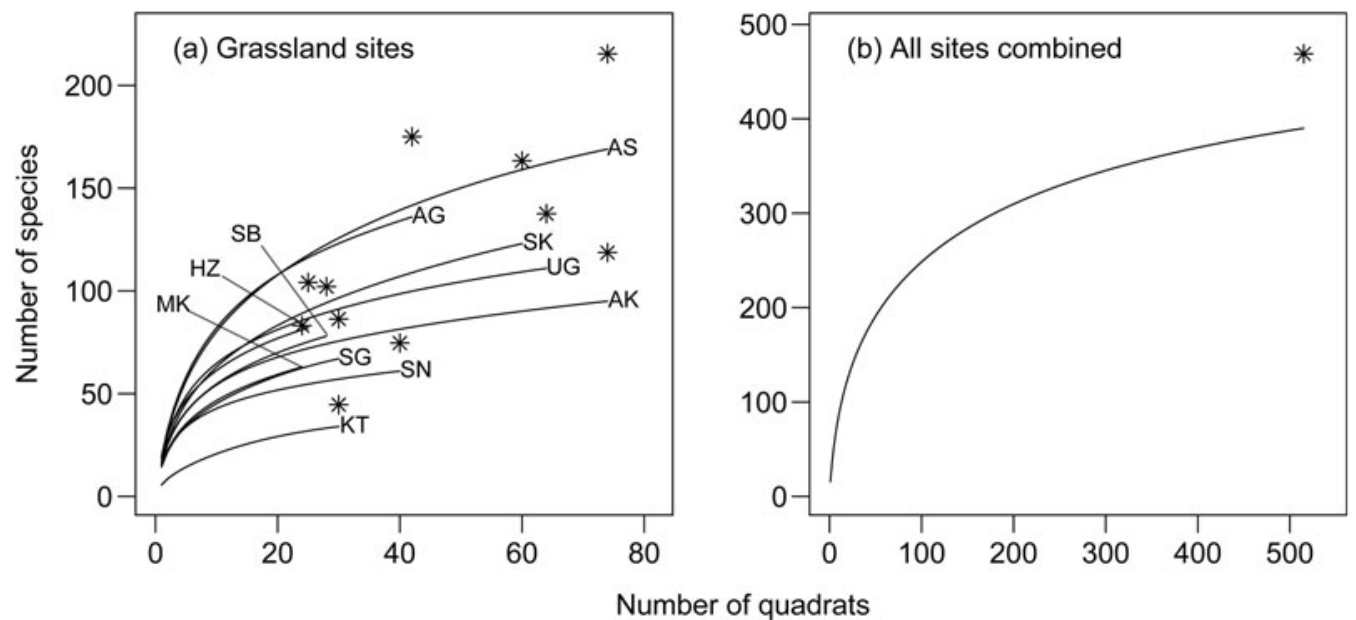

FIG. 2 Species accumulation curves (a) for each grassland site, and (b) fitted to all sites. Asterisks indicate the first-order jackknife estimates of total richness. See Table 1 for site codes.

(a) All species

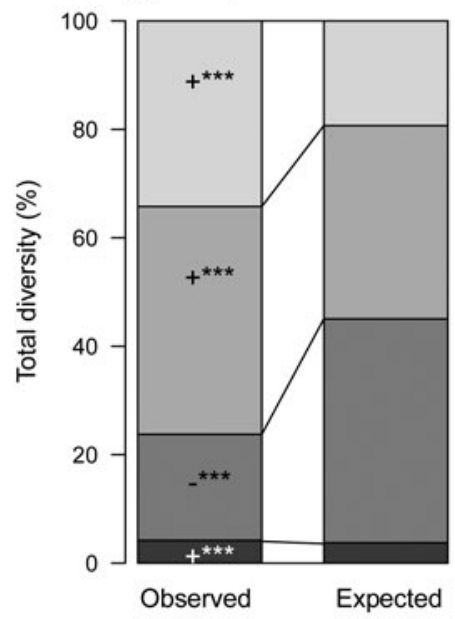

(b) Grassland species

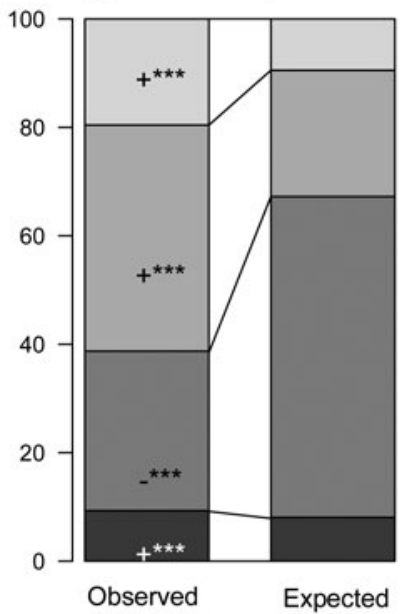

(c) Red Listed species

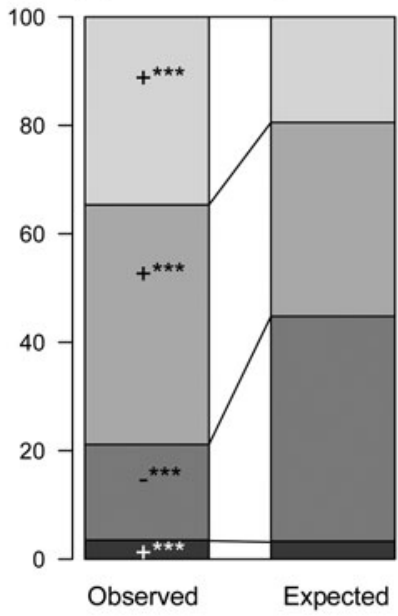

$\alpha 1$ (Within quadrats) $\square \beta 1$ (Among quadrats) $\square \beta 2$ (Among grasslands) $\square \beta 3$ (Between regions)

FIG. 3 Additive partitioning of diversity. Proportion of total species diversity accounted for by $\alpha$ and $\beta$ components at three spatial scales (regions, grasslands and quadrats), for (a) all species, (b) grassland species, and (c) Red Listed species. +, the observed value is statistically higher than the expected; - , the observed value is statistically lower than the expected; ${ }^{\star *}, P<0.001$.

species and Red Listed species. The second-ranked spatial scale for grassland species was among quadrats $\left(\beta_{1}\right)$, whereas for all species and Red Listed species, between-regions diversity $\left(\beta_{3}\right)$ ranked second among the contributors. Previous studies (Crist et al., 2003; Gering et al., 2003, Gabriel et al., 2006, Sasaki et al., 2012) have shown similar patterns of species partitioning (i.e. widespread distributions of common species, and regionally specific distributions of rare species). Most grassland species are typical of semi-natural grasslands and occur widely in this ecosystem across Japan. Miscanthus sinensis, Lysimachia clethroides Duby, Potentilla freyniana Bornm. and Ixeridium dentatum (Thunb. ex Thunb.) Tzvelev occurred in all 11 grasslands that we studied. However, species richness within quadrats was highly variable, ranging from 4 (Kawatabi) to 14 (Mt Sanbe) for grassland species (Fig. 2). Grassland management activities (e.g. burning and mowing) increase habitat heterogeneity within grasslands, thereby enhancing local species diversity (Uchida \& Ushimaru, 2015). Topographical variability within grasslands may also relate to the impact of burning or mowing and help maintain high diversities of grassland species at small spatial scales. Unlike the grassland species, most Red Listed taxa are by definition narrowly distributed; threatened species include local endemics and relic species. Adenophora triphylla (Thunb.) A. DC. var. triphylla was recorded only in the grasslands of western Japan (Supplementary Table $\mathrm{S}_{1}$ ). The proportions of various spatial scales contributing to diversity in the 
ecosystem studied were similar for Red Listed species and the overall community complement, implying that Red Listed species drive the patterns of the entire community (Gering et al., 2003; Müller \& Goßner, 2010). Species conservation efforts that make use of area protection protocols, such as those used for national parks, are often considered to be inadequate for the preservation of narrowly distributed species (Gaston \& Fuller, 2009; Watson et al., 2011). Our findings indicate that grassland species and Red Listed species are probably best protected by different conservation strategies. The conservation of grassland species requires ongoing routine management within each grassland, but the conservation of Red Listed species calls for the maintenance of the unique attributes of each grassland within a regional perspective.

\section{Implications for biodiversity conservation}

Our findings emphasize the need for a nationwide perspective on the conservation of plant diversity in remnant seminatural grasslands. A nationwide approach is beginning to develop in Japan, mostly in relation to bird communities within forest and grassland ecosystems (Yamaura et al., 2009; Katayama et al., 2014). Although the remnant montane semi-natural grasslands of Japan (most of which are located within national parks or quasi-national parks) are protected from land development, regular maintenance (i.e. burning and mowing) has ended or declined as the human population has decreased and managers have aged. The high risk of accidents caused by burning, and the high cost of continuing management activities have also accelerated the abandonment of semi-natural grasslands (Valkó et al., 2014). We found that preserving the beta diversity of individual grasslands is indispensable for nationwide conservation of plant species diversity. Thus, we suggest several potentially effective nationwide approaches. Firstly, a compensatory practice of offsetting species diversity losses in particular grasslands by gains in other locations (Kiesecker et al., 2009, 2010), implemented in some countries, is not a viable strategy (Apostolopoulou \& Adams, 2017). The species diversities of individual grasslands cannot be replaced by diversities of other grasslands because each grassland is unique. Secondly, restoration efforts should be allocated broadly across remnant semi-natural grasslands to boost the numbers of grassland and Red Listed species. Thirdly, strengthening regional cooperation is essential for effective and efficient conservation (Pouzols et al., 2014), especially for Red Listed species. These nationwide perspectives on diversity conservation strategies will be useful for conservation efforts in other remnant and isolated ecosystems. In conclusion, we have highlighted the importance of strengthening local preservation and restoration activities within each grassland, and nationwide strategies for conserving Red Listed species in remnant semi-natural grassland communities.

\section{Acknowledgements}

We are grateful to $\mathrm{Yu}$ Yoshihara (Mie University) for providing field data, and to Yoshiko Kobayashi (Hokkaido University), Takeshi Osawa (National Institute for Agro-Environmental Sciences), Taiki Masui (Gifu University) and the members of the grassland research group in western Japan for their help on our field survey. Dr Martin Fisher and two anonymous reviewers provided valuable comments. This work was supported financially by Environment Research and Technology Development Funds (D-1001, 1-1401). MA was funded by the Japan Society for the Promotion of Science (no. 25740048).

\section{Author contributions}

AK, TFK and MA conceived and designed the surveys and analysed the data. AK, TFK, YK and SH conducted the surveys. All authors contributed to the writing of the article.

\section{References}

Allan, J.D. (1975) Components of diversity. Oecologia, 18, 359-367. Apostolopoulou, E. \& Adams, W.M. (2017) Biodiversity offsetting and conservation: reframing nature to save it. Oryx, 51, 23-31.

Auestad, I., Rydgren, K. \& ØKLAnd, R.H. (2008) Scale-dependence of vegetation-environment relationships in semi-natural grasslands. Journal of Vegetation Science, 19, 139-148.

Bacaro, G., Altobelli, A., Cameletti, M., Ciccarelli, D., Martellos, S., Palmer, M.W. et al. (2016) Incorporating spatial autocorrelation in rarefaction methods: implications for ecologists and conservation biologists. Ecological Indicators, 69, 233-238.

Bacaro, G., Maccherini, S., Chiarucci, A., Jentsch, A., Rocchini, D., Torri, D. et al. (2015) Distributional patterns of endemic, native and alien species along a roadside elevation gradient in Tenerife, Canary Islands. Community Ecology, 16, 223-234.

Bennie, J., Hill, M.O., Baxter, R. \& Huntley, B. (2006) Influence of slope and aspect on long-term vegetation change in British chalk grasslands. Journal of Ecology, 94, 355-368.

Chandy, S., Gibson, D.J. \& Robertson, P.A. (2006) Additive partitioning of diversity across hierarchical spatial scales in a forested landscape. Journal of Applied Ecology, 43, 792-801.

Chiarucci, A., Bacaro, G., Filibeck, G., Landi, S., Maccherini, S. \& Scoppola, A. (2012) Scale dependence of plant species richness in a network of protected areas. Biodiversity and Conservation, 21, $503-516$.

Chiarucci, A., Bacaro, G., Rocchini, D. \& Fattorini, L. (2008) Discovering and rediscovering the sample-based rarefaction formula in the ecological literature. Community Ecology, 9, 121-123. Chinacci, A., Bacaro, G., Rocchini, D., Ricotta, C., Palmer, M. \& SCHEINER, S. (2009) Spatially constrained rarefaction: incorporating the autocorrelated structure of biological communities into sample-based rarefaction. Community Ecology, 10, 209-214. 
Coetzee, B.W.T., Gaston, K.J. \& Chown, S.L. (2014) Local scale comparisons of biodiversity as a test for global protected area ecological performance: a meta-analysis. PLoS ONE, 9(8), e105824.

Crist, T.O., Veech, J.A., Gering, J.C. \& Summerville, K.S. (2003) Partitioning species diversity across landscapes and regions: a hierarchical analysis of $\alpha, \beta$, and $\gamma$ diversity. The American Naturalist, 162, 734-743.

Flohre, A., Fischer, C., Aavik, T., Bengtsson, J., Berendse, F., Bommarco, R. et al. (2011) Agricultural intensification and biodiversity partitioning in European landscapes comparing plants, carabids, and birds. Ecological Applications, 21, 1772-1781.

Gabriel, D., Roschewitz, I., Tscharntke, T. \& Thies, C. (2006) Beta diversity at different spatial scales: plant communities in organic and conventional agriculture. Ecological Applications, 16, 2011-2021.

Gaston, K.J. \& Fuller, R.A. (2009) The sizes of species' geographic ranges. Journal of Applied Ecology, 46, 1-9.

Gering, J.C., Crist, T.O. \& Veech, J.A. (2003) Additive partitioning of species diversity across multiple spatial scales: implications for regional conservation of biodiversity. Conservation Biology, 17, 488-499.

Gibson, D.J., Seastedt, T.R. \& Briggs, J.M. (1993) Management practices in tallgrass prairie: large- and small-scale experimental effects on species composition. Journal of Applied Ecology, 30, 247-255.

Grman, E., Bassett, T. \& Brudvig, L.A. (2013) Confronting contingency in restoration: management and site history determine outcomes of assembling prairies, but site characteristics and landscape context have little effect. Journal of Applied Ecology, 50, 1234-1243.

Groves, C.R., Jensen, D.B., Valutis, L.L., Redford, K.H., Shaffer, M.L., ScotT, J.M. et al. (2002) Planning for biodiversity conservation: putting conservation science into practice. BioScience, 52, 499-512.

Hansson, M. \& Fogelfors, H. (2000) Management of a semi-natural grassland; results from a 15-year-old experiment in southern Sweden. Journal of Vegetation Science, 11, 31-38.

Jost, L. (2007) Partitioning diversity into independent alpha and beta components. Ecology, 88, 2427-2439.

Jost, L., DeVries, P., Walla, T., Greeney, H., Chao, A. \& Ricotta, C. (2010) Partitioning diversity for conservation analyses. Diversity and Distributions, 16, 65-76.

Kahmen, A., Perner, J., Audorff, V., Weisser, W. \& Buchmann, N. (2005) Effects of plant diversity, community composition and environmental parameters on productivity in montane European grasslands. Oecologia, 142, 606-615.

Kahmen, S., Poschlod, P. \& Schreiber, K.F. (2002) Conservation management of calcareous grasslands. Changes in plant species composition and response of functional traits during 25 years. Biological Conservation, 104, 319-328.

Katayama, N., Amano, T., Naoe, S., Yamakita, T., Komatsu, I., TAKAGAWA, S.I. et al. (2014) Landscape heterogeneity-biodiversity relationship: effect of range size. PLoS ONE, 9(3), e93359.

Kiesecker, J.M., Copeland, H., Pocewicz, A. \& McKenney, B. (2010) Development by design: blending landscape-level planning with the mitigation hierarchy. Frontiers in Ecology and the Environment, 8, 261-266.

Kiesecker, J.M., Copeland, H., Pocewicz, A., Nibbelink, N., McKenney, B., Dahlke, J. et al. (2009) A framework for implementing biodiversity offsets: selecting sites and determining scale. BioScience, 59, 77-84.

Kobayashi, S. (1973) The species-area relation. I. A model for discrete sampling. Researches on Population Ecology, 15, 223-237.

Koyanagi, T.F. \& FURUKAWA, T. (2013) Nation-wide agrarian depopulation threatens semi-natural grassland species in Japan: sub-national application of the Red List Index. Biological Conservation, 167, 1-8.

Koyanagi, T., Kusumoto, Y., Hiradate, S., Morita, S., Yokogawa, M., Takahashi, Y. \& Sato, C. (2013) New method for extracting plant indicators based on their adaptive responses to management practices: application to semi-natural and artificial grassland data. Applied Vegetation Science, 16, 95-109.

LANDE, R. (1996) Statistics and partitioning of species diversity, and similarity among multiple communities. Oikos, 76, 5-13.

Lennon, J.J., Beale, C.M., Reid, C.L., Kent, M. \& Pakeman, R.J. (2011) Are richness patterns of common and rare species equally well explained by environmental variables? Ecography, 34, 529-539.

Luoto, M., Virkkala, R. \& Heikkinen, R.K. (2007) The role of land cover in bioclimatic models depends on spatial resolution. Global Ecology and Biogeography, 16, 34-42.

MacDougall, A.S. \& Turkington, R. (2007) Does the type of disturbance matter when restoring disturbance-dependent grasslands? Restoration Ecology, 15, 263-272.

Maekawa, F. (1949) Makinoesia and its bearing to Oriental Asiatic flora. The Journal of Japanese Botany, 24, 91-96.

Marini, L., Scotton, M., Klimek, S., Isselstein, J. \& Pecile, A. (2007) Effects of local factors on plant species richness and composition of Alpine meadows. Agriculture, Ecosystems \& Environment, 119, 281-288.

Martin, L.M., Moloney, K.A. \& Wilsey, B.J. (2005) An assessment of grassland restoration success using species diversity components. Journal of Applied Ecology, 42, 327-336.

Ministry of The Environment, Government of Japan (2012) The 4th Version of the Japanese Red Lists on 9 Taxonomic Groups. Ministry of the Environment Government of Japan, Tokyo. [In Japanese]

Múller, J. \& Goßner, M.M. (2010) Three-dimensional partitioning of diversity informs state-wide strategies for the conservation of saproxylic beetles. Biological Conservation, 143, $625-633$.

Myklestad, Å. \& S Ætersdal, M. (2004) The importance of traditional meadow management techniques for conservation of vascular plant species richness in Norway. Biological Conservation, 118, 133-139.

Nagata, Y.K. \& Ushimaru, A. (2016) Traditional burning and mowing practices support high grassland plant diversity by providing intermediate levels of vegetation height and soil $\mathrm{pH}$. Applied Vegetation Science, 19, 567-577.

OGURA, J. (2006) The transition of grassland area in Japan. Journal of Kyoto Seika University, 30, 160-172. [In Japanese]

Oksanen, J., Blanchet, F.G., Kindt, R., Legendre, P., Minchin, P. R., O'Hara, R.B. et al. (2016) Vegan: Community Ecology Package, R Package Version 2.3-5. Http://CRAN.R-project.org/package=vegan.

Palmer, M.W. (1990) The estimation of species richness by extrapolation. Ecology, 71, 1195-1198.

Pouzols, M.F., Toivonen, T., Di Minin, E., Kukkala, A.S., Kullberg, P., Kuusterä, J. et al. (2014) Global protected area expansion is compromised by projected land-use and parochialism. Nature, 516, 383-386.

Pyкälä, J., Luoto, M., Heikkinen, R.K. \& Kontula, T. (2005) Plant species richness and persistence of rare plants in abandoned semi-natural grasslands in northern Europe. Basic and Applied Ecology, 6, 25-33.

Sasaki, T., Katabuchi, M., Kamiyama, C., Shimazaki, M., Nakashizuka, T. \& Hikosaka, K. (2012) Diversity partitioning of moorland plant communities across hierarchical spatial scales. Biodiversity and Conservation, 21, 1577-1588. 
Schmera, D. \& Podani, J. (2013) Components of beta diversity in hierarchical sampling designs: a new approach. Ecological Indicators, 26, 126-136.

Summerville, K.S., Boulware, M.J., Veech, J.A. \& Crist, T.O. (2003) Spatial variation in species diversity and composition of forest Lepidoptera in eastern deciduous forests of North America. Conservation Biology, 17, 1045-1057.

TAKAHASHI, Y. (2004) Vegetation management for conservation and restoration of semi-natural grassland. Grassland Science, 50, 99-106.

The Plant List (2013) Http://www.theplantlist.org/ [accessed 5 February 2016].

UChida, K. \& Ushimaru, A. (2015) Land abandonment and intensification diminish spatial and temporal $\beta$-diversity of grassland plants and herbivorous insects within paddy terraces. Journal of Applied Ecology, 52, 1033-1043.

VAlkó, O., Török, P., DeÁk, B. \& Tóthmérész, B. (2014) Review: prospects and limitations of prescribed burning as a management tool in European grasslands. Basic and Applied Ecology, 15, 26-33.

Veech, J.A., Summerville, K.S., Crist, T.O. \& Gering, J.C. (2002) The additive partitioning of species diversity: recent revival of an old idea. Oikos, 99, 3-9.

Vellak, A.I.N., Tuvi, E.L., Reier, Ü., Kalamees, R., Roosaluste, E., Zobel, M. \& PÄrtel, M. (2009) Past and present effectiveness of protected areas for conservation of naturally and anthropogenically rare plant species. Conservation Biology, 23, 750-757.

Wagner, H.H., Wildi, O. \& Ewald, K.C. (2000) Additive partitioning of plant species diversity in an agricultural mosaic landscape. Landscape Ecology, 15, 219-227.
Watson, J.E.M., Evans, M.C., Carwardine, J., Fuller, R.A., Joseph, L.N. \& SEGAn, D.B. et al. (2011) The capacity of Australia's protected-area system to represent threatened species. Conservation Biology, 25, 324-332.

Yamato, M., Ema, K. \& TAKedA, Y. (2013) Relationships between species richness, species composition and area of fragmented semi-natural grasslands in central Kinki District. Vegetation Science, 30, 119-126.

Yamaura, Y., Ikeno, S., SAno, M., Okabe, K. \& Ozaki, K. (2009) Bird responses to broad-leaved forest patch area in a plantation landscape across seasons. Biological Conservation, 142, 2155-2165. YList (2003) Http://ylist.info [accessed 5 February 2016].

\section{Biographical sketches}

AsUKa Koyama is a plant ecologist, whose research interests include biodiversity conservation and ecological management. Tомоуо KoyANAGI is a landscape ecologist interested in landscape changes of semi-natural grasslands, and the efficient use of traditional knowledge and plant resources. MUNEMITSU AKASAKA's work focuses on planning for biodiversity conservation and biological invasions. Yoshinobu Kusumoto is an expert in vegetation science, and researches the environmental assessment of agricultural and grassland ecosystems. Syuntaro Hiradate is a specialist in soil analysis. MASAYUKI TAKADA's work focuses on environmental assessment and environmental policy, particularly in relation to wetland and grassland ecosystems. КІмІко ОКАве is an ecologist and manages several research projects on biodiversity evaluation and biological invasions. 